\title{
On the Mechanism of Cavitation Damage
}

\author{
By M. S. PLESSET ${ }^{1}$ AND A. T. ELLIS, ${ }^{2}$ PASADENA, CALIF.
}

A new method for producing cavitation damage in the laboratory is described in which the test specimen has no mechanical accelerations applied to it in contrast with the conventional magnetostriction device. Alternating pressures are generated in the water over the specimen by exciting a resonance in the "water cavity." By this means the effects of cavitation have been studied for a variety of materials. Photomicrographs have been taken of several ordinary (polycrystalline) specimens and also of zinc monocrystals. The zinc monocrystal has been exposed to cavitation damage on its basal plane and also on its twinning plane. $\mathrm{X}$-ray analyses have been made of polycrystalline specimens with various exposures to cavitation. The results show that plastic deformation occurs in the specimens so that the damage results from cold-work of the material which leads to fatigue and failure. A variety of materials has been exposed to intense cavitation for extended periods to get a relative determination of their resistance to cavitation damage. It is found that, roughly speaking, hard materials of high tensile strengths are the most resistant to damage. While this survey is not complete, it has been found that titanium 150-A and tungsten are the most resistant to damage of the materials tested. Cavitation-damage studies, which have been carried out in liquid toluene and in a helium atmosphere, show that chemical effects can be, at most, of secondary significance.

\section{INTRODUCTION}

$\mathrm{N}$ UMEROUS studies have been made of the cavitation process and the mechanism of cavitation damage. No attempt will be made here to give a bibliography on this subject; reference may be made, however, to the monograph by Nowotny ${ }^{3}$ and to an investigation of damage with a magnetostriction oscillator by Kornfeld and Suvorov. ${ }^{4}$ In laboratory studies of cavitation damage it is often desirable to accelerate the damage rate. It has long been recognized that the cavitation produced by pressure variations at relatively high frequencies will produce damage more rapidly than the cavitation under ordinary flow conditions. The procedure which has been universally used consists in high-frequency acceleration of the test specimen relative to the liquid medium. These accelerations are obtained by application of the magnetostrictive effect in a nickel rod to the end of which the test specimen is attached The liquid partakes of this accelerating motion and heavy cavitation is produced. ${ }^{3,4}$ In such experiments the quantities measured are the displacement of the test surface and its frequency. Weight loss of the specimen also is determined as a function of exposure time to the cavitation field.

\footnotetext{
${ }^{1}$ Professor of Applied Mechanics, California Institute of Technology. Mem. ASME.

2 Senior Research Fellow, California Institute of Technology.

8 "Werkstoffzerstörung durch Kavitation," by H. Nowotny, Edward Brothers, Inc., Ann Arbor, Mich., 1946.

4 "On the Destructive Action of Cavitation," by M. Kornfeld and

L. Suvorov, Journal of Applied Physics, vol. 15, 1944, p. 495.

Contributed by the Hydraulic Division and presented at the Annual Meeting, New York, N. Y., November 28-December 3, 1954, of The American Society of Mechanical Engineers.

Note: Statements and opinions advanced in papers are to be understood as individual expressions of their authors and not those of the Society. Manuscript received at ASME Headquarters, August 11, 1954. Paper No. 54-A-76.
}

A new method for generating cavitation damage has been developed and studied by one of the authors and appears to have some important advantages for this type of investigation. While this method has been described, ${ }^{5}$ it is necessary to give a brief description of it here so that the results of the present study may be more easily interpreted.

\section{Pressure Variations Produced in a Resonant Cavity}

The apparatus used consists of a cylindrical beaker containing water with a barium titanate ring just below the surface, Fig. 1. If an alternating electric field is applied across the conducting coatings on the inner and outer surfaces of the ring, the volume of the ring oscillates with the applied electric field. At the proper

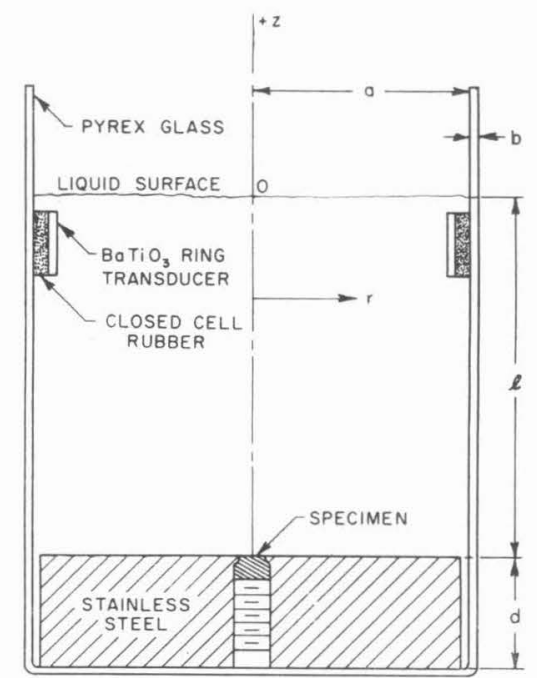

Fig. 1 Diagram of Cylindrical Beaker and Co-Ordinate SYstem

frequency of the electric field, a standing wave pattern is set up in such a way that a large pressure amplitude is produced at the center of the bottom plate. The pressure variation is sufficient to produce cavitation over the specimen with a sinusoidal voltage of amplitude between 100 and 200 volts. For some of the experiments, the oscillation frequency was 18,000 cycles; for the remainder of the studies, with a beaker of different dimensions, the oscillation frequency was 24,000 cycles. Fig. 2 shows the well-defined cavitation cloud over the surface of the specimen. Fig. 3 shows the complete apparatus with the audio oscillator, the power amplifier, and the beaker.

The acoustic theory for the pressure field in a cylindrical cavity is easily developed. The fluid velocity $\bar{v}$ and the time varying part of the pressure $p$ are related to the velocity potential $\varphi$ by $\bar{v}=-\nabla \varphi$ and $p=\rho_{w} \partial \varphi / \partial t$, where $\rho_{w}$ is the density of water. Viscous and streaming effects are neglected. One seeks a characteristic solution of the wave equation

5 "Production of Accelerated Cavitation Damage by an Acoustic Field in a Cylindrical Cavity," by A. T. Ellis, Hydrodynamics Laboratory Report No. 21-14, California Institute of Technology, Pasadena, Calif. 


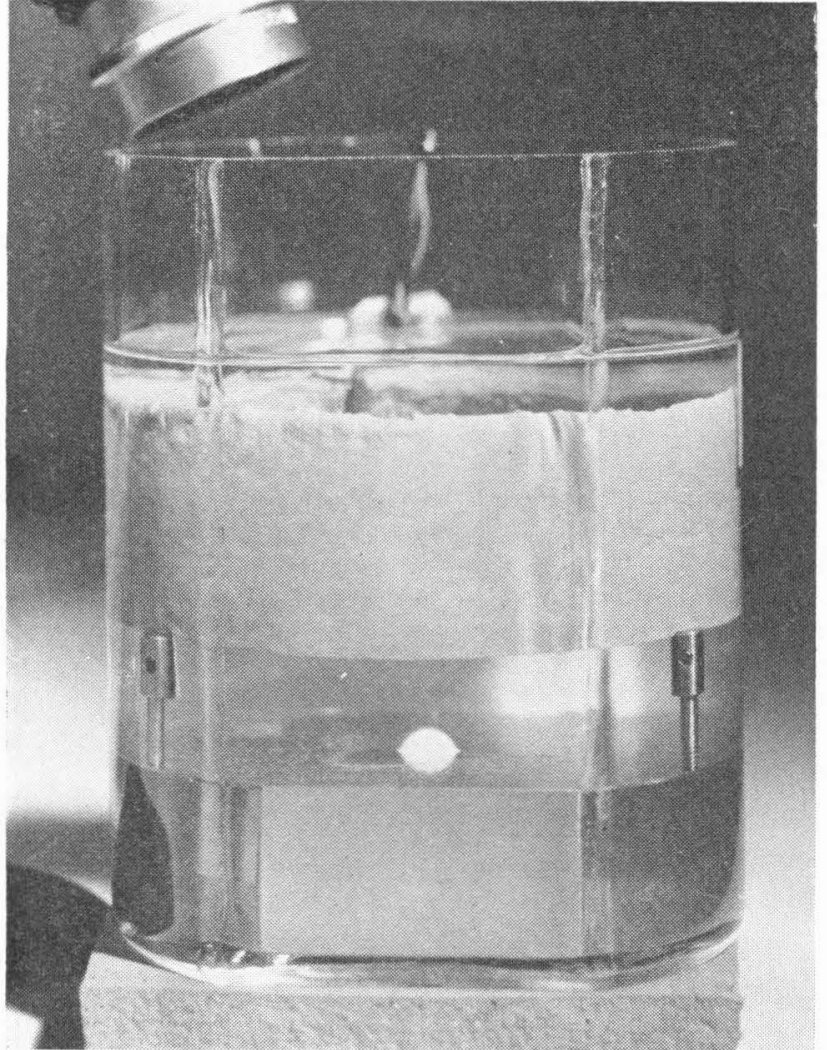

Fig. 2 Beaker in Operation Showing Cavitation Cloud

$$
\Delta \varphi-\frac{1}{c^{2}} \frac{\partial^{2} \varphi}{\partial t^{2}}=0
$$

of the form $\varphi=R(r) Q(z) e^{i \omega t}$ where $c$ is the sound velocity in water, $\omega / 2 \pi$ is the exciting frequency, $r$ is the radial distance from the axis of cylindrical symmetry, and $z$ is the distance measured along this axis, Fig. 1. The origin of $z$ is at the water surface and the positive direction of $z$ is upward. The boundary conditions may be described as follows: The massive steel plate at the bottom of the container is assumed to move as a free rigid mass. Under this assumption, Newton's second law of motion gives a condition on the velocity potential at the interface of the liquid and the steel plate

$$
\rho_{w} \frac{\partial \varphi}{\partial t}-\frac{d}{d t}\left(\frac{\partial \varphi}{\partial z}\right)\left(\rho_{s} d\right)=0, \quad \text { at } z=-l
$$

or

$$
\varphi-\frac{\partial \varphi}{\partial z}\left(\frac{\rho_{s} d}{\rho_{w}}\right)=0, \quad \text { at } z=-l \ldots \ldots \ldots
$$

where $\rho_{s}$ is the density of the steel plate and $d$ is its thickness. The boundary condition at the beaker wall is determined under the assumption that this wall is under simple hoop tension. The force per unit length of the cylindrical wall is $E b d a / a$ where $E$ is the Young's modulus of the glass (pyrex), $b$ is its thickness, and $a$ is its unstrained radius. Then the force equation at the wall, $r=a$, leads to the boundary condition

$$
\varphi-\left(\frac{E}{a^{2} \omega^{2}}-\rho_{g}\right) \frac{b}{\rho_{w}} \frac{\partial \varphi}{\partial r}=0, \quad \text { at } r=a \ldots \ldots
$$

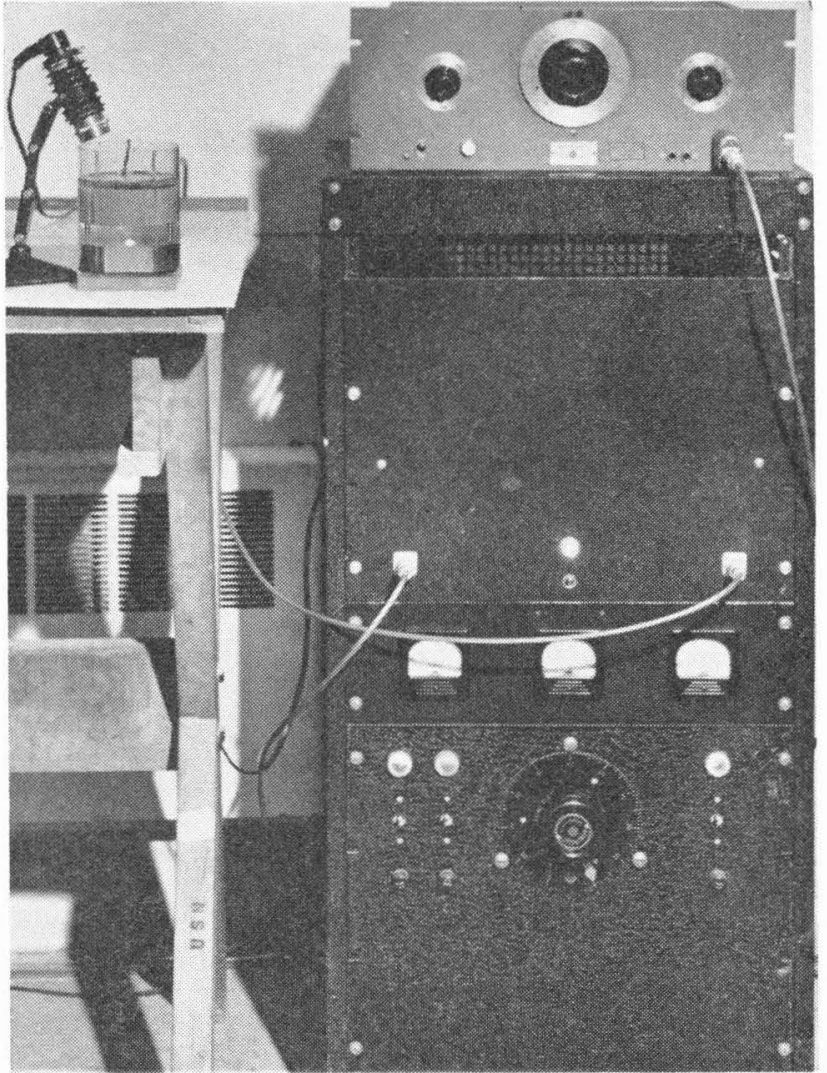

Fig. 3 Complete Apparatus Including Oscillator, Amplifier, AND BEAKER

where $\rho_{o}$ is the density of the glass. There is finally the boundary condition at the free surface of the water

$$
\varphi=0, \text { at } z=0 .
$$

The characteristic solutions which satisfy these boundary conditions are

$$
\varphi_{m n}=A_{m n} \sin \beta_{m} z J_{0}\left[\left(\frac{\omega^{2}{ }_{m n}}{c^{2}}-\beta_{m}\right)^{1 / 3} r\right] \ldots \ldots
$$

where $J_{0}$ is the Bessel function of zero order and $\beta_{m}$ is a solution of the equation

$$
\frac{\tan \beta l}{\beta}=-\frac{\rho_{s} d}{\rho_{w}}
$$

The angular frequency $\omega_{m n}$ is given by

$$
\omega_{m n}=c\left[\left(\frac{\alpha_{m n}}{a}\right)^{2}+\beta_{m}^{2}\right]^{1 / 2}
$$

where the constant $\alpha_{m n}$ is determined from the solution of the equation

$$
\frac{J_{0}(\alpha)}{\alpha J_{1}(\alpha)}=\frac{b}{a}\left[\frac{\rho_{a}}{\rho_{w}}-\frac{E}{\rho_{w} c^{2}\left(\alpha^{2}+a^{2} \beta_{m}^{2}\right)}\right]
$$

A series of characteristic frequencies has been computed and has been compared with measured resonant frequencies for the water cavity. Agreement between theoretical and observed values is very good. A comparison of theoretical and ob- 
TABLE 1 THEORETICAL AND OBSERVED CHARACTERISTIC ANGULAR FREQUENCIES

Dimensions of the pyrex beaker are $a=4.83 \mathrm{~cm}, b=0.254 \mathrm{~cm}, d=2.54$ $\mathrm{cm}, l=8.13 \mathrm{~cm}$. Young's modulus for pyrex $E=6.76 \times 10^{11} \mathrm{dynes} / \mathrm{cm}^{2}$; velocity of sound in water at room temperature $c=1.52 \times 10^{5} \mathrm{~cm} / \mathrm{sec}$; density of water $\rho_{w}=1 \mathrm{gm} / \mathrm{cc}$, density of stainless-steel bottom plate $\rho_{s}=$ $7.93 \mathrm{gm} / \mathrm{cc}$, density of pyrex $p_{0}=2.23 \mathrm{gm} / \mathrm{cc}$.

$\begin{array}{lcr}\omega_{m n} & \text { Calculated values } & \text { Measured values } \\ \omega_{11} & 88 & 85 \\ \omega_{21} & 117 & 117 \\ \omega_{31} & 168 & 167 \\ \omega_{11} & 217 & 213 \\ \omega_{12} & 167 & 171 \\ \omega_{12} & 253 & \\ \omega_{14} & 340 & \\ \omega_{22} & 184 & \end{array}$

served characteristic frequencies for specific beaker dimensions is shown in Table 1. The pressure amplitude has been measured as a function of $r$ and $z$. These variations also agree well with those determined by Equation [5]. Of immediate practical importance is the fact that the most easily excited mode has the largest pressure amplitude at the center of the bottom plate. Thus the cavitation cloud is readily confined to the small region over the specimen. Fig. 4 shows the cavitation bubble cloud at two different points of the pressure cycle. The upper picture shows the bubble cloud near the pressure maximum and the lower picture shows the bubble cloud near the pressure minimum. Fig. 5 gives somewhat greater detail in the bubble cloud near the maximum (the lower half of the picture is a reflection of the bubble cloud in the stainless-steel plate).

In the opinion of the authors, the method used here for producing cavitation damage in the laboratory has several important advantages over the magnetostriction oscillator method. The use of the barium titanate electric transducer to generate standing pressure waves in the water cavity results in an apparatus which is very simple electrically and which, at the same time, is appreciably less expensive than the magnetostriction oscillator. The present device is stable in operation and requires a minimum of maintenance and attention. A wide range of frequencies is readily available. Of perhaps greater significance is the fact that one has here an efficient way of producing the oscillating cavitation field. As a consequence, there is negligible heating of the water or the test specimen even in very long exposures at high powers. Under heavy cavitation conditions the water temperature has been observed to rise less than $3 \mathrm{deg} \mathrm{C}$ in $1 \mathrm{hr}$. It also should be remarked that there is negligible streaming of the water in the container and there is no pumping action on the water. An additional consideration which led the authors to the adoption of this resonant "cavity" procedure was the fact that the test specimen is stationary throughout its exposure to cavitation. No mechanical acceleration stresses are applied to the specimen as there are when it is attached to a magnetostriction rod. As a specimen receives cavitation damage, small regions of reduced strength are produced and these small regions might be torn out of the specimen under mechanical acceleration. From the point of view of an analytic consideration of the cavitation bubble behavior, it also would seem advantageous to have a stationary boundary and no gross water velocity or acceleration.

For the photomicrographic observations and for the $x$-ray analyses of cavitation damage, the specimens were mounted flush in the base plate, Fig. 1. Under these conditions the cavitation cloud has a diameter of approximately 0.37 in., Fig. 2 .

\section{Photomicrographic Observations of Cavitation Damage}

A series of experiments were made to observe the optical changes in the surface of a specimen under cavitation damage. Fig. 6 shows the surface of a nickel specimen after a 5-min exposure to the cavitation cloud. It is of interest to note the unevenness of the damaged surface. This appearance of microscopic "hills and valleys" is characteristic of the behavior of very soft materials.

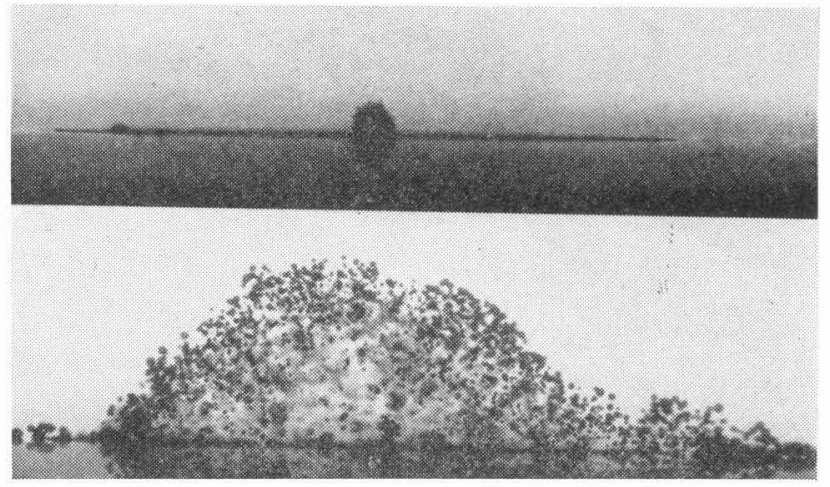

Fig. 4 Bubble Cloud at Two Different Points of Pressure Cycle

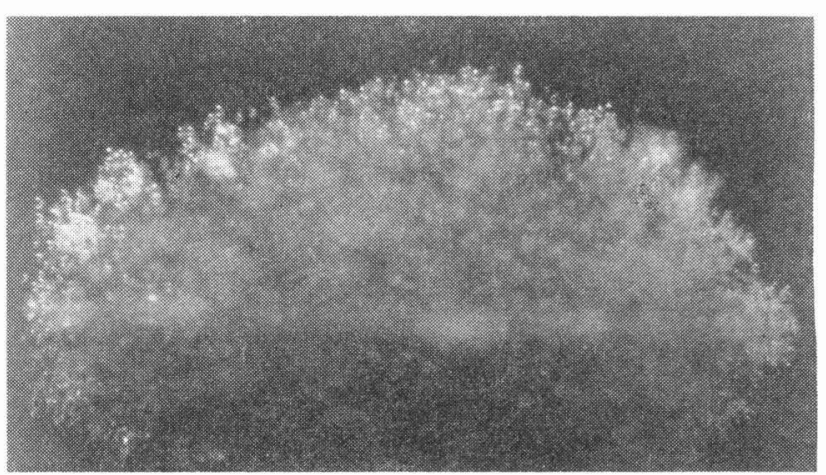

Fig. 5 Bubble Cloud With Top Lighting

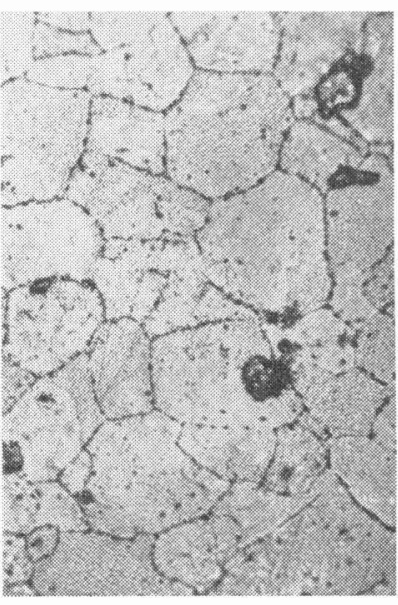

(a) Before exposure to eavitation

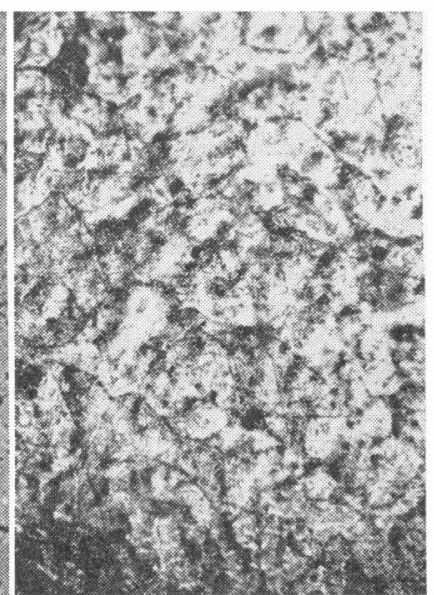

(b) After 5-min exposure to cavitation
Fig. 6 Photomicrograph of Nickel Specimen; $\times 560$

Fig. 7 shows a stainless-steel specimen which is of somewhat greater interest, metallurgically, since slip lines are clearly in evidence. These results may be compared with the photomicrographs of a harder material, an example of which is titanium 130-A, Fig. 8. No optical alteration in the surface of this material is evident even after prolonged exposure to the cavitation cloud.

This series of photomicrographs is typical of results with other materials. The very soft materials quickly show a microscopic hill-and-valley effect and not much can be deduced regarding 


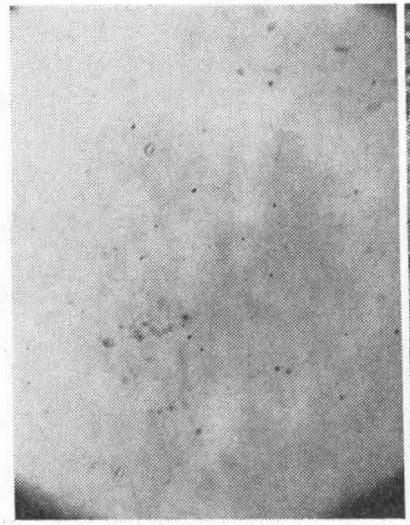

(a) Before exposure to cavitation

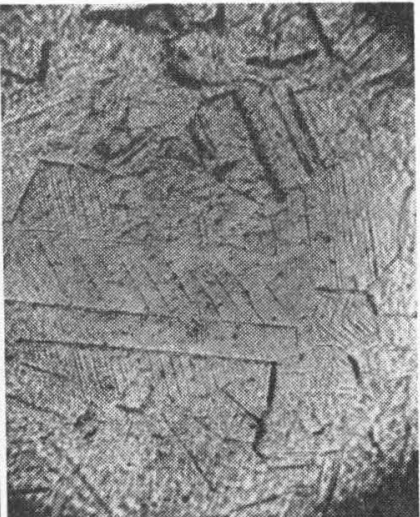

(b) After 5-min exposure to cavitation

Fig. 7 Photomicrograph of Stainless-Steel Specimen; $\times 560$

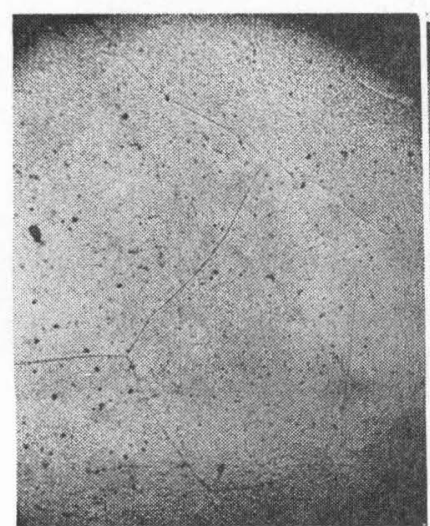

(a) Before exposure to cavitation

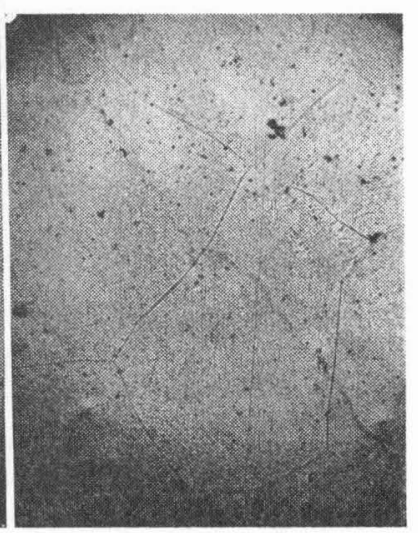

(b) After 2-hr exposure to cavitation

Fig. 8 Photomicrograph of Titanium Specimen (With 7 Per Cent Manganese); $\times 200$

crystallographic changes. In materials of intermediate hardness, this hill-and-valley effect is not so evident and some evidence of crystallographic changes may be observed. In the very hard materials no ehange is evident. In these studies the cavitation damage was kept sufficiently light so that no significant weight loss in the specimens was obtained. Optical observations and photomicrography appear to be of limited value for a polycrystalline material which is the usual state of a specimen.

Photomicrography can be a powerful tool in revealing alterations in crystal structure if the specimen is a single crystal. A zine monocrystal was made available to the authors through the kindness of Dr. Thad Vreeland, Jr., of the Engineering Division, California Institute of Technology. A basal plane (0001 plane) was obtained for exposure to cavitation by cleavage in liquid nitrogen. When this surface is stressed by the cavitation field, the hexagonal structure of the exposed plane becomes evident.

Fig. 9 shows this effect when the surface is exposed to a cloud of extent small compared with the exposed area. The nearly point application of the cavitation stress brings out the hexagonal structure very readily. Fig. 10 shows a basal plane in a zinc erystal before exposure to cavitation. Figs. 11, 12, and 13 show this same specimen after exposure to a broad cloud of cavitation covering the specimen. Similar observations have been made on a zinc crystal cut parallel to a twinning plane and the results are shown

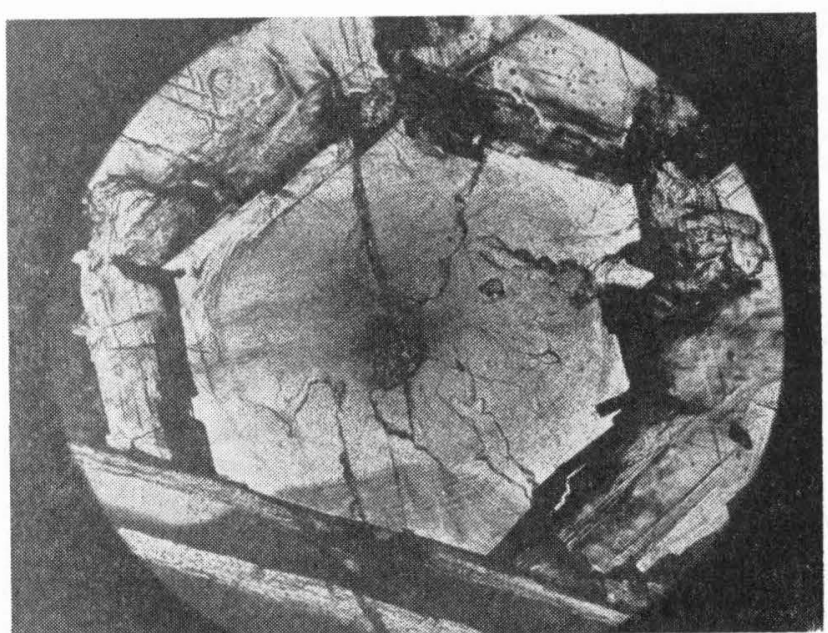

Fig. 9 Center of Damaged Area on (0001) Plane of a Single Zinc Crystal After 10-Min Exposure to $1 / 16$-In-Diam Cavitation Bubble Cloud; $\times 38$

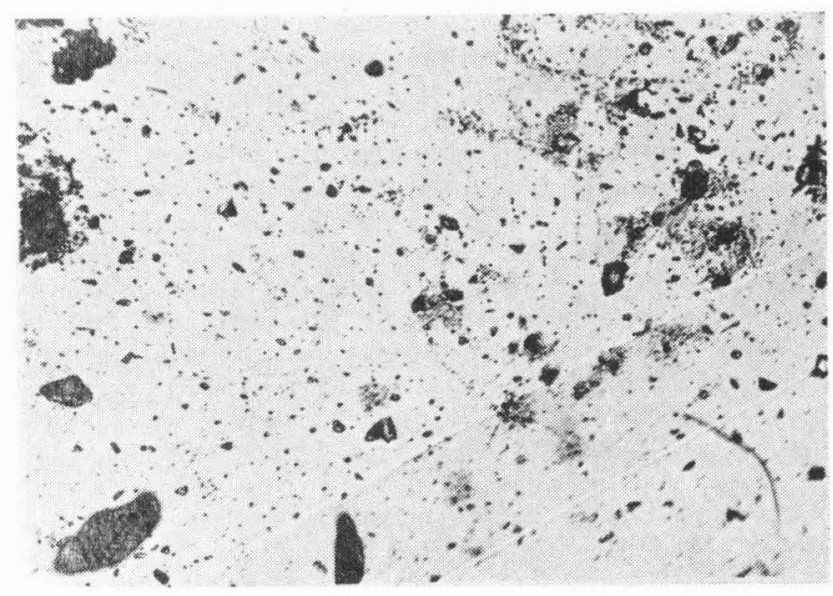

Fig. 10 Annealed Surface of a Zinc Monocrystal Cleaved Along a Basal Plane-Undamaged; $\times 250$

in Figs. 14, 15, and 16. The geometry of the zinc crystal is sketched in Fig. 17.

While some of the previous photomicrographs gave evidence that cavitation damage is initiated through plastic deformation of the exposed specimen, very striking and detailed additional evidence of this mechanism are obtained from these studies on the monocrystal. In particular, severe plastic deformation of the zinc monocrystal is found in the form of twinning in the specimens exposed on a slip plane and in the form of slip in the specimens exposed on a twinning plane.

\section{X-Ray Observations of Cavitation Damage}

Changes in structure can be observed readily in a polycrystalline specimen by the use of $\mathrm{x}$-rays. For this reason a series of observations were taken on ordinary specimens exposed to cavitation damage. Fig. 18 shows $x$-ray diffraction patterns from a nickel specimen before exposure to cavitation, after 2 -sec exposure to a broad cavitation cloud, and after 10-sec exposure. The blurring of the patterns, which is quite marked after only 2-sec exposure, shows that plastic deformation of the nickel microcrystals starts almost immediately upon exposure to eavitation. Fig. 19 shows similar results in brass. These specimens showed no significant 


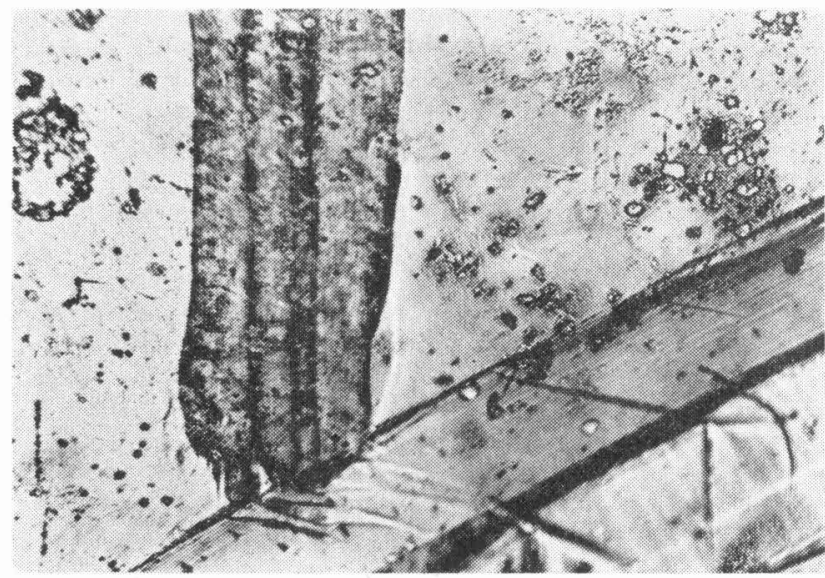

Fig. 11 Annealed Surface of a Zinc Monocrystal Cleaved Along a Basal Plane

Note appearance of many new twin bands, cross twins, and hexagonal pits, 15 -sec exposure; $\times 250$.

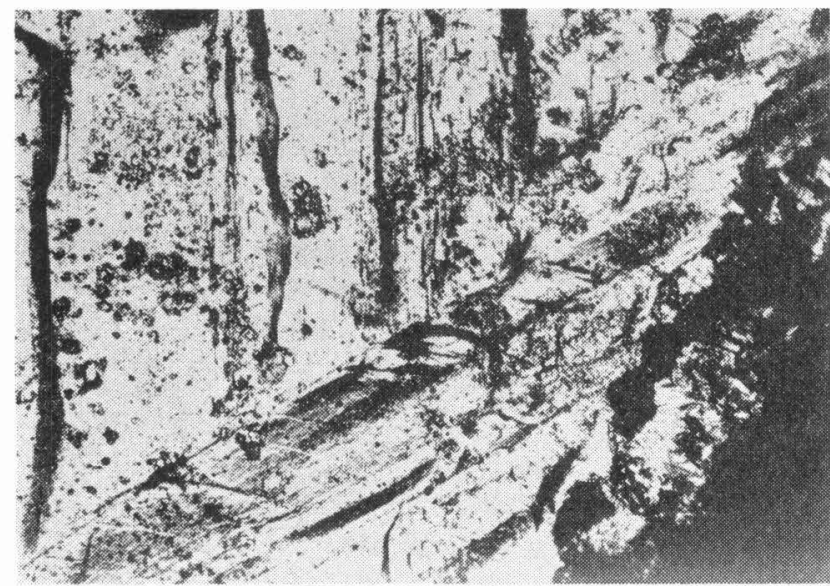

Fig. 13 Annealed Surface of a Zinc Monocrystal Cleaved Along a Basal Plane-Development of Cavitation Damage (Note slip lines in twin bands and growth of pits 80 -sec exposure; $\times 100$.)

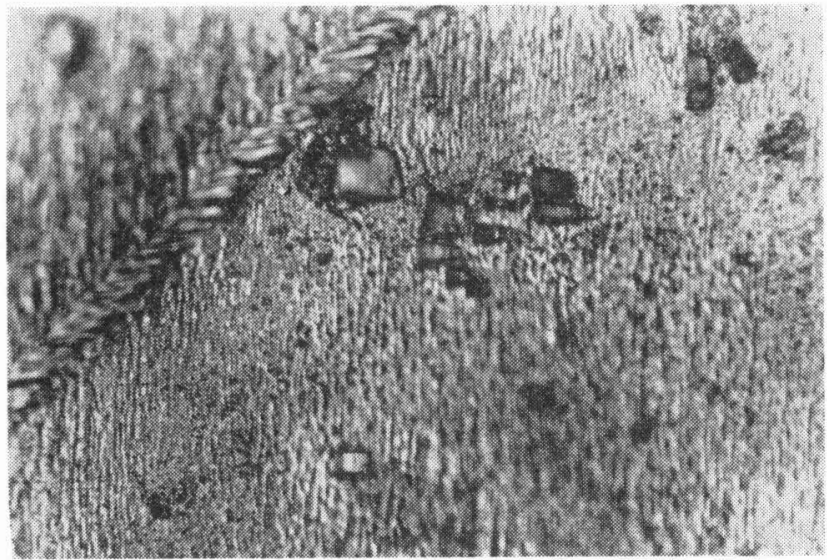

Fig. 15 Polished and Annfaled Surface of a Zinc Monocrystal Cut Parallel to a Twinning Plane

(Texture of surface is due to preferred attack of etchant. Ropy line across surface is a twin band due to cutting the specimen-note rectangular pits

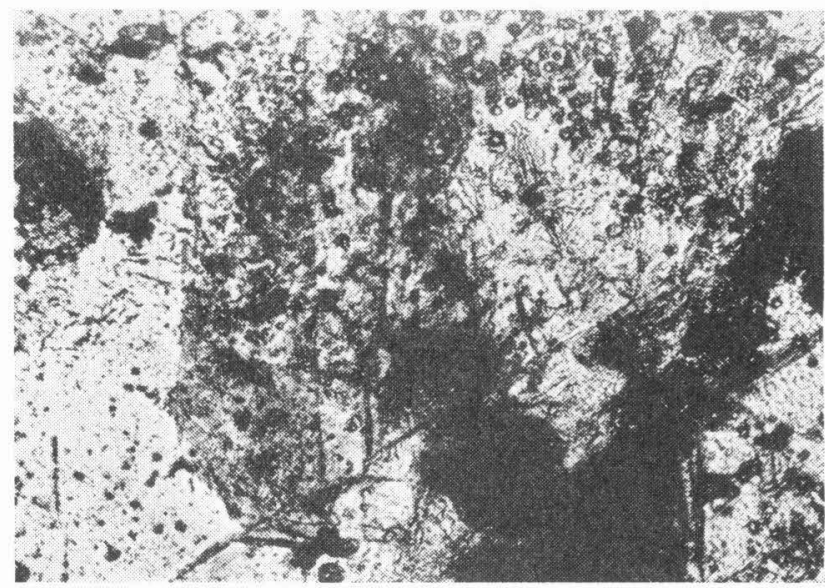

Fig. 12 Annealed Surface of a Zinc Monocrystal Cleaved Along a Basal Plane

(Observe the increase in surface roughness and pitting, 30-sec exposure $\times 250$.)

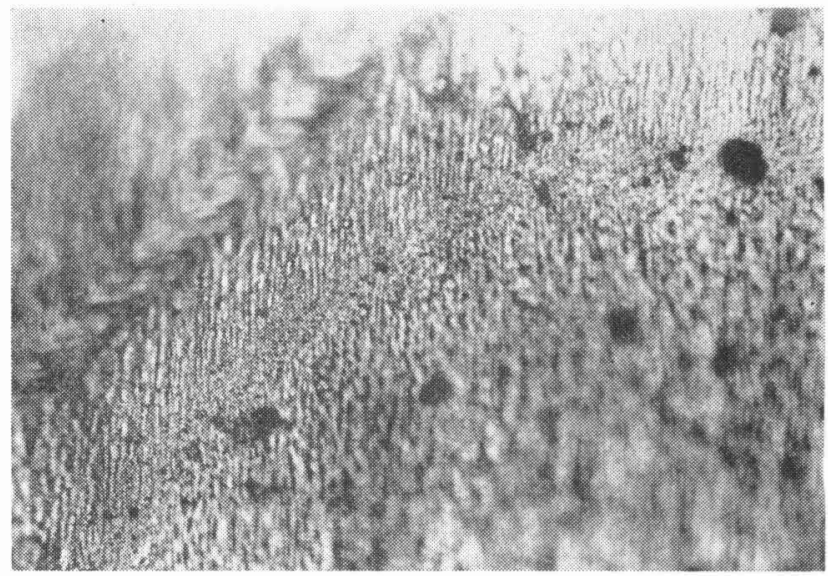

Fig. 14 Polished and Annealed Surface of a Zinc Monocrystal Cut Parallel to a Twinning Plane

(Texture of surface is due to preferred attack of etchant. The ropy line across the surface is a twin band due to cutting the specimen, undamaged;

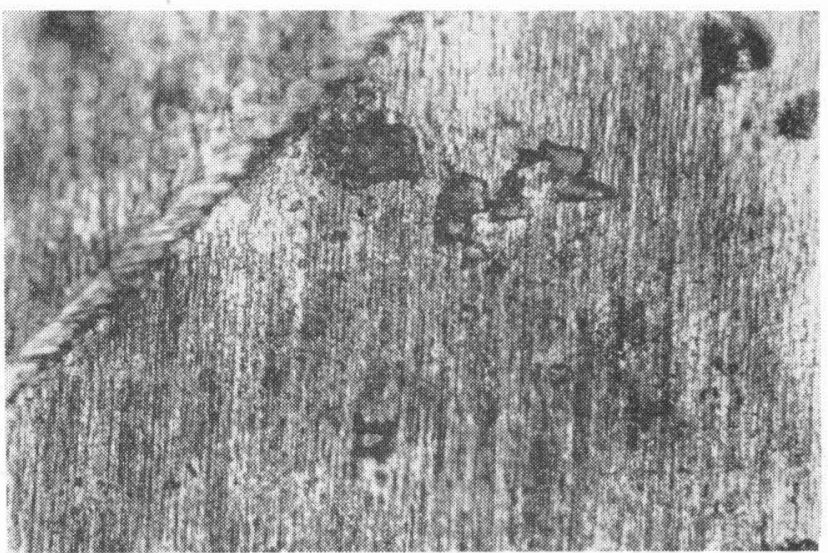

Fig. 16 Polished and Annealed Surface of a Zinc Monocrystai Cut Parallel to a Twinning Plane

(Texture of surface is due to preferred attack of etchant. Ropy line across surface is a twin band due to cutting the specimen, 210 -sec exposure; $\times 500$. 


\section{Geometry of a Zinc Crystal}

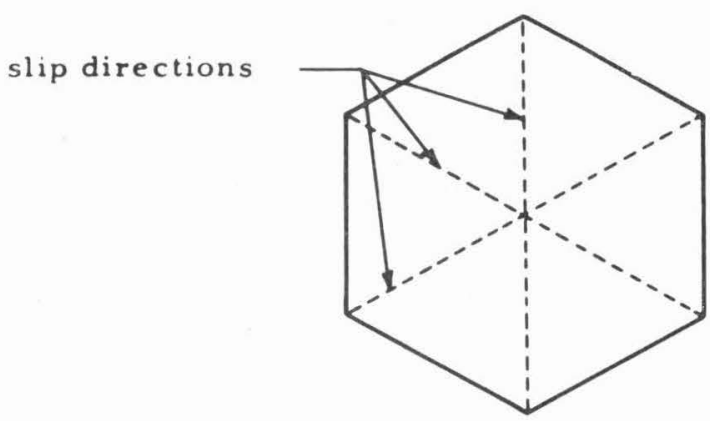

Basal plane projection

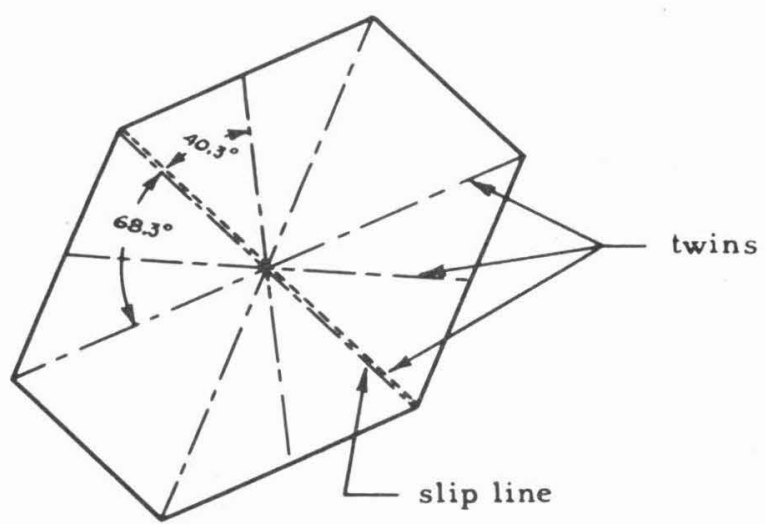

Projection of the twinning plane

$$
\begin{aligned}
& \text { twinning plane }=(10 T 2) \\
& \text { slip plane }=(0001) \\
& \text { slip direction }=(11 \overline{2} 0)
\end{aligned}
$$

Fig. 17 Geometry of a Zinc Crystal

optical change or weight loss; yet the alteration in structure is very evident from the $\mathrm{x}$-ray observations.

To determine the depth of the region of plastic deformation, thin layers were removed from the surface until the x-ray pattern returned approximately to its original configuration. Layers were "peeled off" uniformly by the process of electrolytic polishing. These results are illustrated in Figs. 20 and 21 for nickel, and in Fig. 22 for brass. A similar study was made of a pure titanium specimen and is illustrated in Fig. 23. Here the x-ray diffraction spots are replaced by circular lines since the specimen was rotated while being exposed to the $\mathrm{x}$-ray beam. The broadening of the circular lines shows again the plastic deformation which takes place on exposure to cavitation. To determine the depth of penetration of the region of plastic deformation in titanium, layers were removed in steps by etching until the lines returned approximately to their original sharpness.

The x-ray diffraction patterns in Figs. 18 to 23 show the effects of light exposure to cavitation in a group of metals which are easily damaged. Similar x-ray studies have been made with vanadium, molybdenum, and tungsten which are much more resistant to cavitation damage. As with all the other samples for which $x$-rays have been taken, these specimens were annealed, and the deformation of the lattice structure arising from exposure to cavitation is shown by the blurring of the x-ray diffraction spots, Figs. 24, 25, and 26. While Figs. 20 and 22 show a significant amount of plastic deformation in nickel and brass after a few seconds' exposure to cavitation, a similar amount of deformation takes several minutes for vanadium, approximately an hour for molybdenum, and several hours for tungsten.

The resistance of tungsten to cavitation damage might have been expected in view of its great hardness and high ultimate tensile strength, Table 2. That these properties are not necessary for high resistance to cavitation damage is shown by molybdenum. The molybdenum specimens have a hardness and ultimate tensile strength similar to those of brass, and yet were very much more resistant to cavitation damage. The x-ray studies presented here show that cavitation damage takes place through plastic deformation, or cold-work, of the exposed solid. In some materials, such as nickel or brass, this plastic deformation occurs very quickly; in others, such as molybdenum or tungsten, relatively long exposures are required. The mechanism of plastic deformation demonstrates that the essential property for resistance to cavitation damage is the fatigue resistance of the solid. Further, the fatigue behavior of a solid is related in a complex way to its usually measured properties. It also must be kept in mind that the stresses applied to the solid by cavitation are of very short duration so that the fatigue behavior under low frequency stress application is not necessarily a measure of resistance to cavitation damage. The exceptional resistance of molybdenum to cavitation damage in view of its hardness and tensile strength may be understood from the known lag in the yielding of this solid to an applied stress. Thus, for the short stress pulses produced in cavitation, the deformation of molybdenum may be expected to be reduced.

\section{Rate of Material Loss in Cavitation Damage}

A series of experiments were undertaken to secure a rough measure of resistance to cavitation damage in a group of polycrystalline substances. This series has a definite engineering interest. To get significant damage quickly, the specimens were made with a small tip protruding above the level of the bottom flat plate. By this means the cavitation cloud was concentrated over the end of the tip and did not appear elsewhere; the diameter of the region over which the cavitation cloud extended under these conditions was approximately 0.07 in, With this configuration, the cavitation cloud drilled nearly cylindrical holes in the specimens. The depth of these cylindrical holes for given exposure time is a measure of the resistance to damage. Measurements of this kind are summarized in Table 2. A photograph of a stellite specimen exposed to this concentrated cloud is shown in Fig. 27, and a corresponding photograph of a titanium 150-A specimen is shown in Fig. 28.

\section{Chemical Effects in Cavitation Damage}

There has been considerable speculation that cavitation damage is primarily the result of chemical action. Such a corrosion picture of the damage is in contradiction with the view presented here of the damage arising from cold-work. In order to give further information on this question, a series of experiments were performed in which the cavitation cloud was generated in liquid toluene from which any dissolved air was completely removed. At the same time, helium at $1 \mathrm{~atm}$ was maintained above the liquid. Toluene is known to be a very inert liquid chemically and 


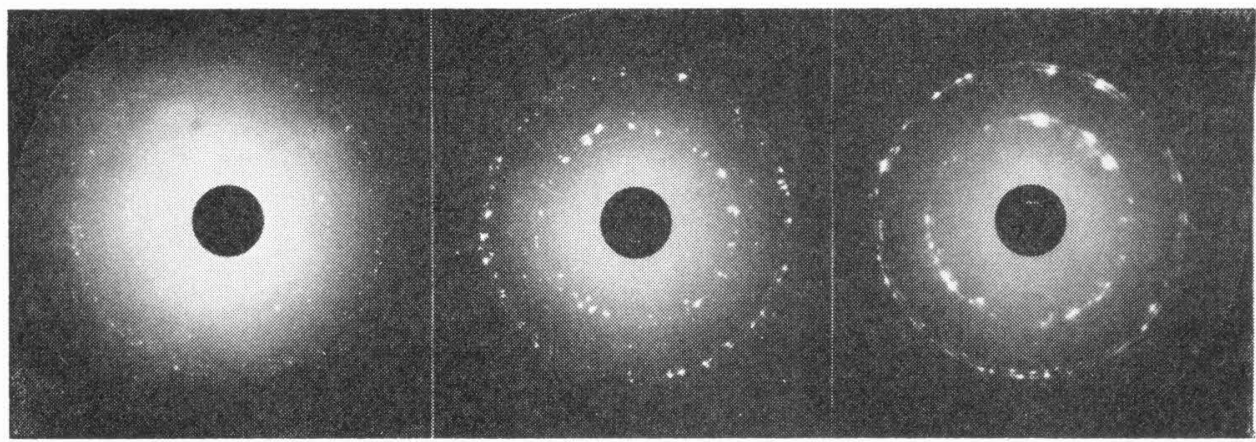

(a) Before exposure

(b) After 2-sec exposure

(c) After 10-sec exposure

Fig. 18 X-Ray Diffraction Pattern of Nickel Specimen Showing Rapid Onset of Cold-Work on Exposure to Cavitation in Water

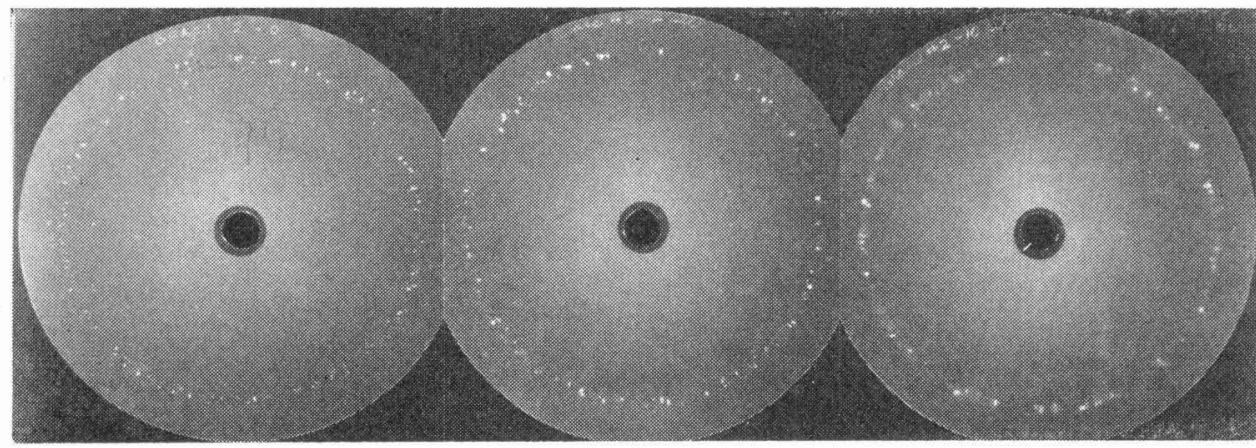

(a) Before exposure

(b) After 2-sec exposure

(c) After 10-sec exposure

Fig. 19 X-Ray Diffraction Pattern of Brass Specimen Showing Rapid Onset of Cold-Work on Exposure to Cavitation

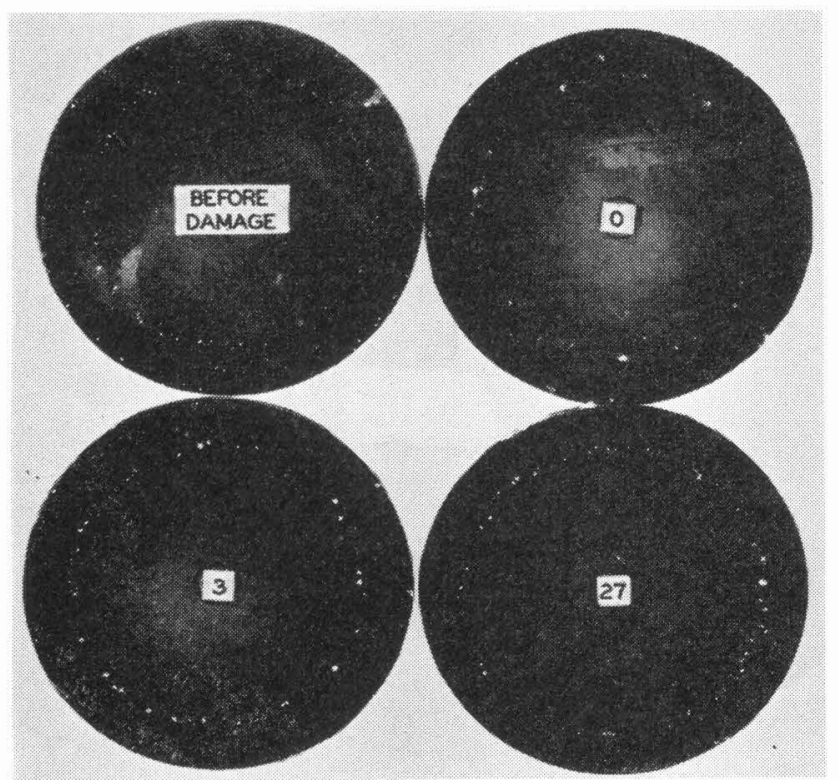

Fig. 20 Annealed Nickel-Damaged 30 Sec-Depth of Layer Removed After Damage Is Shown in Migrons

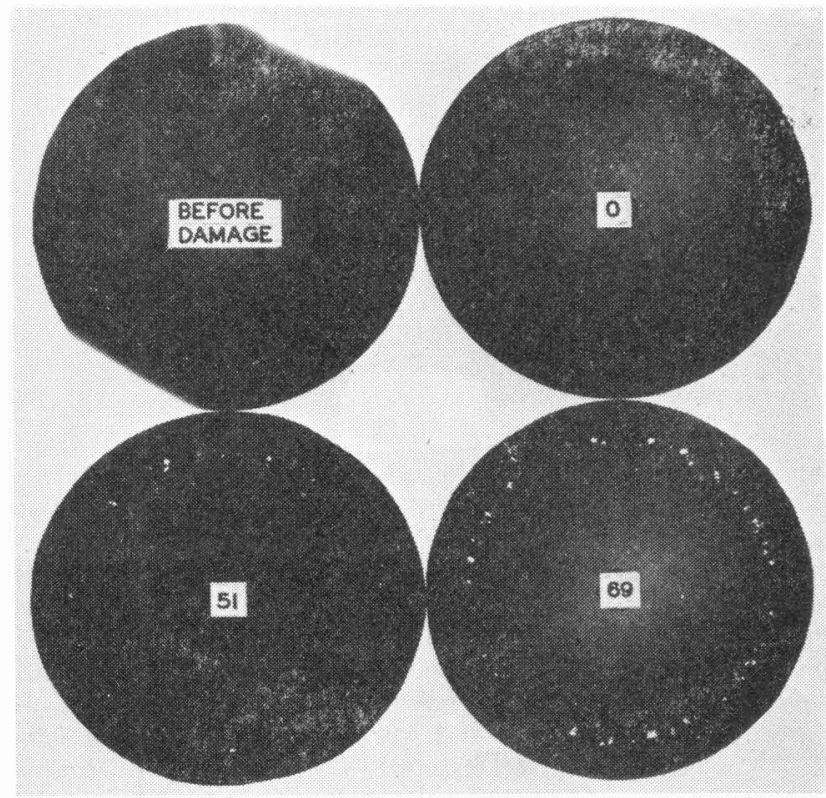

Fig. 21 Annealed Nickel-Damaged 30 Min-Depth of Layer Removed After Damage Is Shown in Microns 


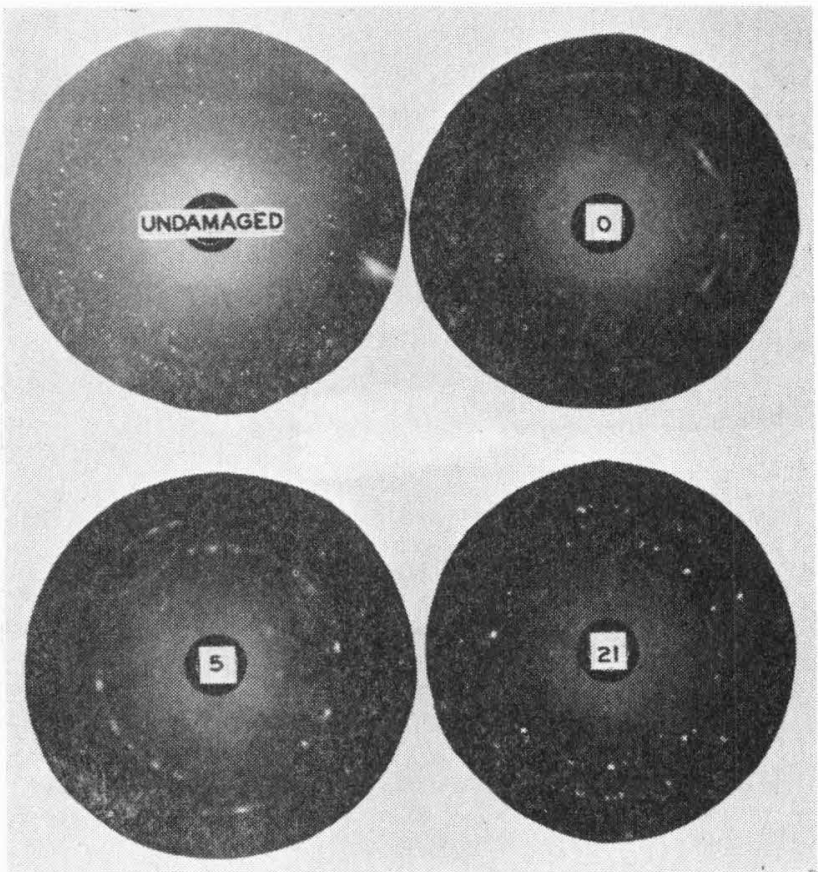

Fig. 22 Annealed Brass-Damaged 30 Min-Depth of Layer Removed After Damage Is Shown in Microns

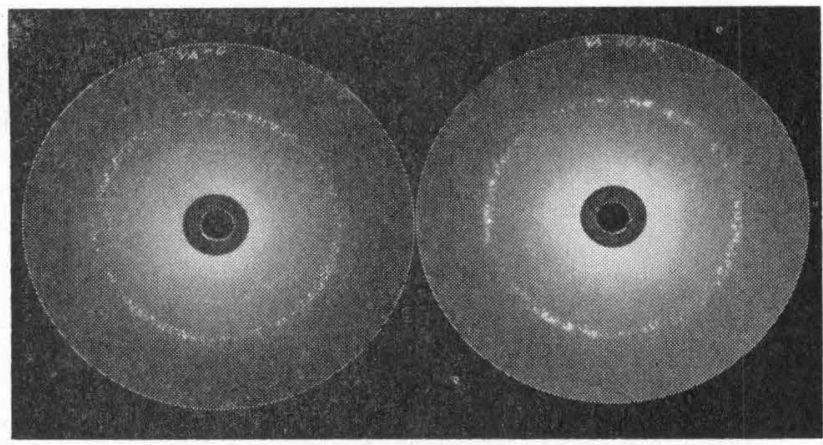

(a) Before exposure

(b) After 30-min exposure

Fig, 24 X-Ray Diffraction Pattern of Vanadium Specimen Showing Cold-Work on Exposure to Cavitation in Water

helium is, of course, an inert gas. Fig. 29 shows a photomicrograph of the surface of a nickel specimen before exposure to cavitation and after 5 -min exposure in liquid toluene. Cavitation damage to the surface is evident. Fig. 30 shows an x-ray diffraction picture of a nickel specimen before exposure to cavitation and after 2-sec exposure in liquid toluene. A comparison of Fig. 30 and the corresponding $\mathrm{x}$-ray pattern obtained with nickel after 2 -sec exposure in water, Fig. 18, shows that essentially the same type and extent of plastic deformation take place. Similar results have been found with stainless steel. It is to be concluded that, in so far as the basic process of cavitation damage is concerned, chemical effects are not of primary significance. It must not be concluded that there are no chemical effects at all; in fact, it is known that a chemically active environment can affect the fatigue properties of a solid material.

\section{Summary and Conclusion}

The apparatus for this study of eavitation damage, in the authors' opinion, is an inexpensive and efficient device for cavita-

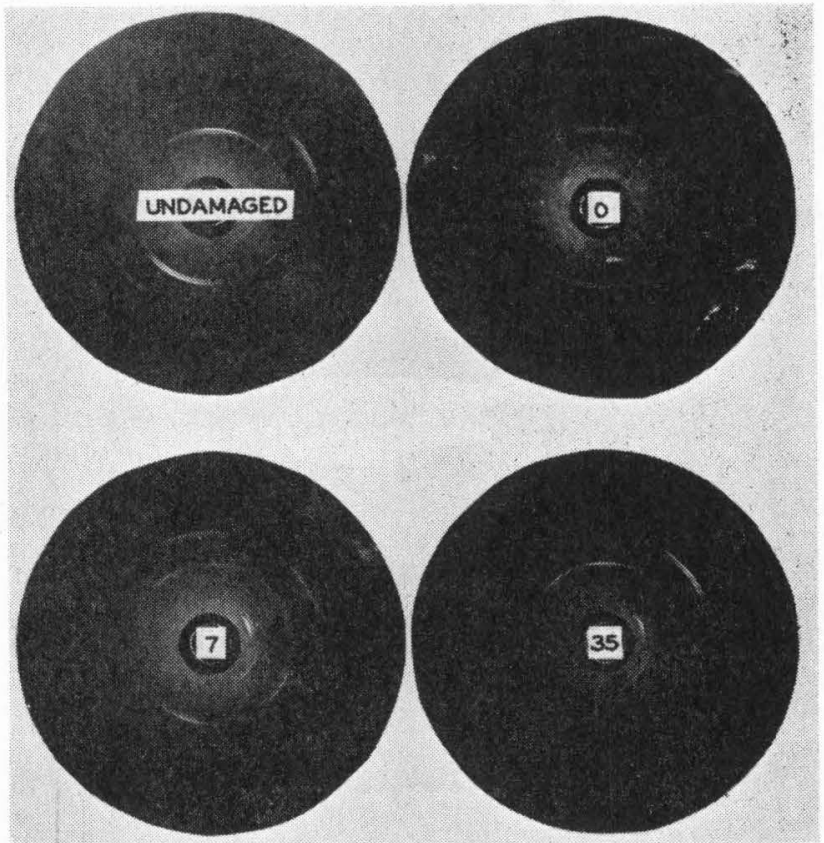

Fig. 23 Pure Annealed Titanium-Damaged 30 Min-Depth of Layer Removed After Damage Is Shown in Microns

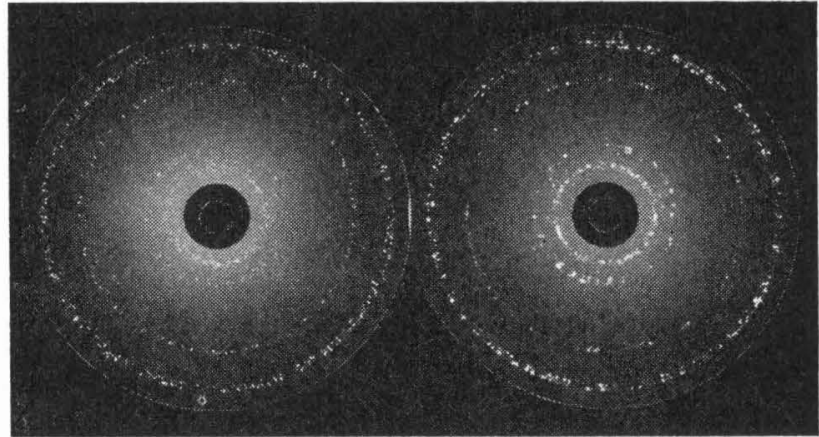

(a) Before exposure

(b) After 1-hr exposure

Fig. 25 X-Ray Diffraction Pattern of Molybdenum Specimen Showing Cold-Work on Exposure to Cavitation in Water

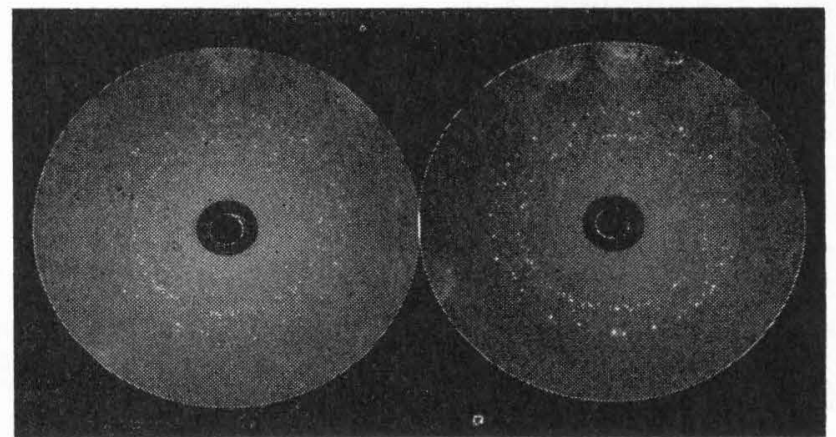

(a) Before exposure

(b) After 5-hr exposure

Fig. 26 X-Ray Diffraction Pattern of Tungsten Specimen Showing Cold-Work on Exposure to Cavitation in Water 
TABLE 2 CHARACTERISTICS OF VARIOUS MATERIALS AND SUMMARY OF CAVITATION DAMAGE SUSTAINED IN TESTS

\begin{tabular}{|c|c|c|c|c|c|c|c|c|c|c|}
\hline $\begin{array}{l}\text { Material (arranged in } \\
\text { order of increasing hard- } \\
\text { ness) composition, }\end{array}$ & Hardness, & $\begin{array}{c}\text { Ultimate } \\
\text { tensile } \\
\text { strength }\end{array}$ & $\begin{array}{l}\text { Modulus } \\
\text { of elas- } \\
\text { ticity } \\
\text { (psi X }\end{array}$ & Dep & pth of & cavitatio & $\begin{array}{l}\text { on dama } \\
\left(10^{-4} \mathrm{~cm}\right.\end{array}$ & ge hole & & crons \\
\hline per cent & Bhn & & & $10 \mathrm{sec}$ & $1 \mathrm{~min}$ & $15 \mathrm{~min}$ & $30 \mathrm{~min}$ & $1 \mathrm{hr}$ & $2 \mathrm{hr}$ & \\
\hline Aluminum (soft). & 16 & 16 & 10 & 10 & 80 & & & & & \\
\hline Titanium (annealed).... & 58 & 79 & 16 & & & 43 & 78 & & & \\
\hline $\begin{array}{l}\text { Nickel . . . . . . . . . . . } \\
\text { Molybdenum. }\end{array}$ & 90 & $\begin{array}{l}50 \\
57\end{array}$ & 30 & & & 80 & 115 & 25 & 60 & 100 \\
\hline Brass, Cu $70, Z_{n} 30 \ldots$ & $\begin{array}{l}120 \\
123\end{array}$ & $\begin{array}{l}57 \\
56\end{array}$ & $\begin{array}{l}50 \\
13\end{array}$ & & 1 & 85 & $\begin{array}{r}10 \\
128\end{array}$ & 25 & 60 & 100 \\
\hline $\begin{array}{l}\text { Stainless steel, Cr 18, } \\
\text { Ni 8.............. }\end{array}$ & 163 & 102 & 29 & & & 15 & 28 & & & \\
\hline Titanium $75-A \ldots \ldots \ldots$ & 20 & 80 & 1 & & & & & $\begin{array}{l}30 \\
32\end{array}$ & 66 & \\
\hline Steel $(4130) \ldots \ldots \ldots \ldots$ & 25 & 130 & 3 & & & & & 32 & 55 & \\
\hline $\begin{array}{l}\text { Tungsten } \\
\text { Titanium } 130-\mathrm{A}, \mathrm{Ti}_{92},\end{array}$ & 350 & 597 & 51 & & & & 0 & 0 & 3 & 12 \\
\hline $\begin{array}{r}\text { Titanium } 130-A, \text { Ti } 92, \\
\text { Mn } 7.9 \ldots \ldots \ldots \ldots \ldots\end{array}$ & 351 & 130 & 16 & & & & 0 & 3 & 16 & \\
\hline Colmonoy & 400 & 61 & & & & & 0 & 3 & 18 & 34 \\
\hline $\begin{array}{r}\text { Titanium } 150-\mathrm{A}, \mathrm{Ti} 96, \\
\mathrm{Cr} 2.7, \mathrm{Fe} 1.3 \ldots \ldots\end{array}$ & 437 & 150 & 16 & & & & 0 & 0 & 3 & 26 \\
\hline Stellite, Co $55, \mathrm{Cr} 33$, W 6 & 495 & 100 & 36 & & & & 0 & 3 & 14 & 29 \\
\hline $\begin{array}{l}\text { Pyrex } \ldots \ldots \ldots \ldots \\
\text { Fused quartz } \ldots \ldots \ldots\end{array}$ & $\begin{array}{l}\text { Moh } 5 \\
\text { Moh } 7\end{array}$ & & $\begin{array}{r}10 \\
9\end{array}$ & & & $\begin{array}{l}120 \\
100\end{array}$ & & & & \\
\hline
\end{tabular}

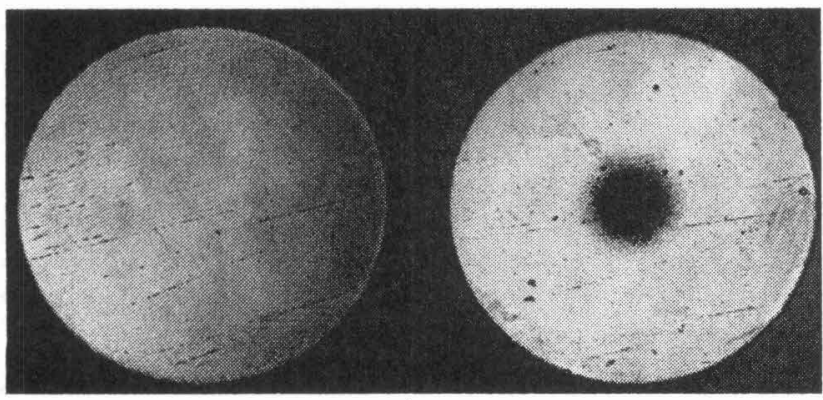

(a) Undamaged

(b) Damaged $1 \mathrm{hr}$

Fig. 27 Stellite Specimen-Magnification $\times 40$

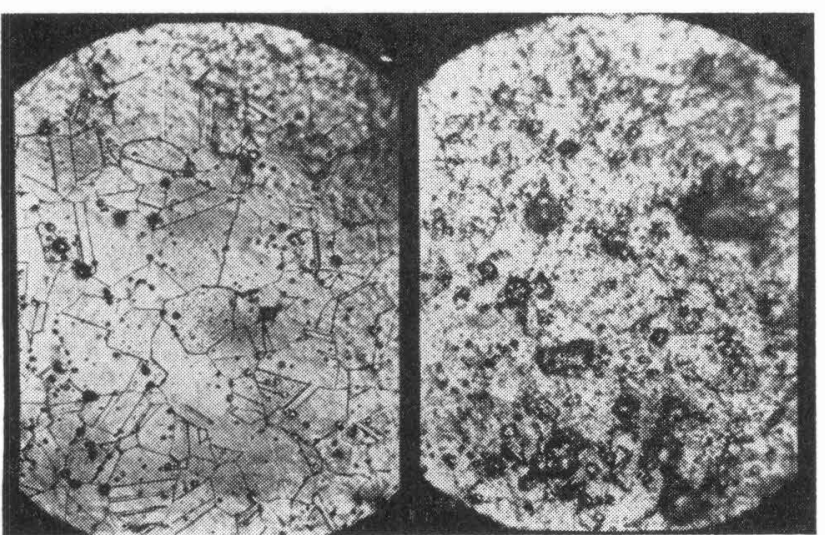

(a) Before exposure

(b) After 5-min exposure

Fig. 29 Annealed and Etched Surface of Nickel Specimen Exposed to Cavitation in Liquid Toluene in a Helium AtmosPHERE

tion research or testing. Cavitation tests are extremely simple, and relative resistance to cavitation damage such as is given in Table 2 is very easily obtained.

Ordinary polycrystalline specimens and pure monocrystals have been exposed to cavitation damage. Photomicrographic examination and $\mathrm{x}$-ray diffraction patterns both show that plastic deformation occurs. This plastic deformation appears to set in almost immediately in soft substances such as nickel, brass, or pure titanium. Since these are substances with ultimate tensile strengths of the order of $50,000 \mathrm{psi}$, it is indicated that cavitation stresses may be at least of this magnitude. On the other hand, the very slow onset of damage in a material such as tungsten or

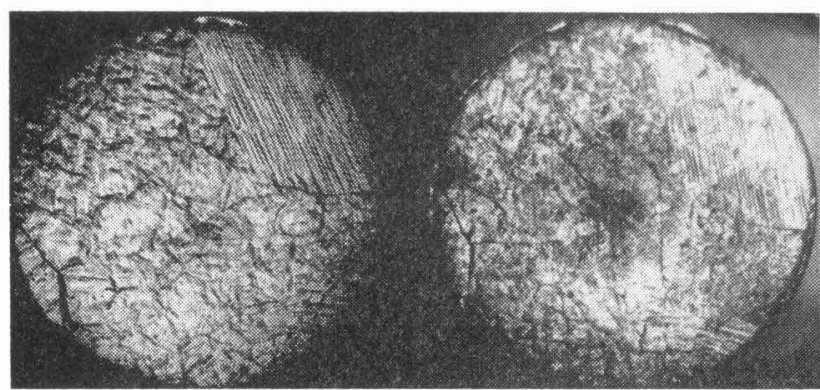

(a) Undamaged

(b) Damaged $1 \mathrm{hr}$

Fig. 28 Titanium 150-A Specimen-Magnification $\times 40$

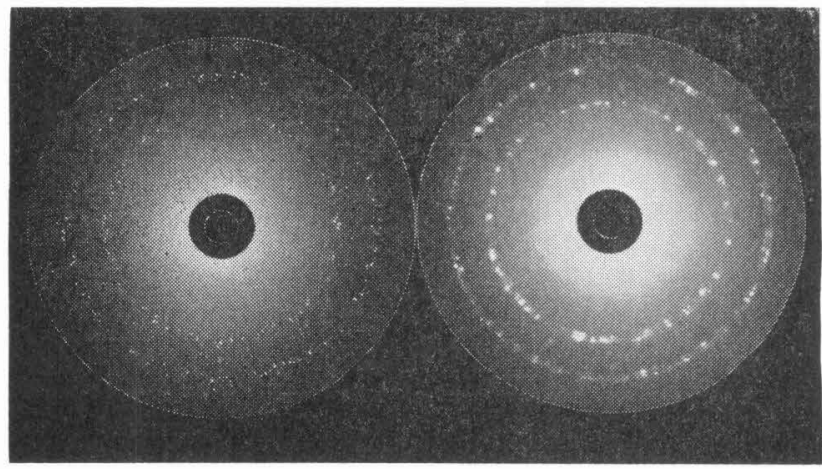

(a) Before exposure

(b) After 2-sec exposure

Fig. 30 X-Ray Diffraction Pattern of Nickel Specimen Showing Rapid Onset of Cold-Work on Exposure to Cavitation in Toluene in a Helium Atmosphere

titanium 150-A with ultimate tensile strengths of the order of 130,000 psi or greater might be taken as an indication that cavitation stresses lie below this magnitude.

It should be emphasized that cavitation damage represents the interaction of a complex of properties of the solid so that consideration of ultimate tensile strengths alone, or of hardness alone, or any other single property would be misleading. The general mechanism of the damage does appear to be reasonably clear. A polycrystalline or monocrystalline specimen exposed to cavitation undergoes eventual or almost immediate plastic deformation, depending on its hardness and yield properties. This plastic deformation is a cold-work of the material which leads to fatigue and failure of portions of the specimen.

The similarity in the plastic deformation produced in a variety 
of specimens with different chemical properties makes it unlikely that chemical action is of particular significance in cavitation damage, at least as produced here. Conclusive additional evidence on this point is furnished by the photomicrographic and $\mathrm{x}$-ray studies of cavitation damage produced in air-free toluene with a helium atmosphere. Toluene and helium are particularly inert substances chemically. These experiments show the same damage effects as are found in water.

\section{AcKNOWLEDGMENTS}

This study was supported by the U. S. Navy Office of Naval Research, Mechanics Branch. The authors wish to express their appreciation to Mr. J. E. Neimark for valuable assistance with the observations on zinc monocrystals. The authors are also greatly indebted to Profs. Pol Duwez and David Wood of the Engineering Division of the California Institute of Technology, not only for making facilities available to them but also for their helpful interest and comments throughout the study.

\section{Discussion}

IRving TAYLOR. ${ }^{6}$ The authors of this splendid paper have very nearly proved that chemical actions play no part in the mechanism of eavitation pitting. Before taking this completely for granted, it is advisable to consider two plausible phenomena that could be important, if secondary.

Not only the most resistant materials but also the mediumresistant materials (vanadium, molybdenum, 4130 steel, stainless steel) showed "incubation periods," in Table 2 of the paper and in the $\mathrm{x}$-ray studies. If these delays are required for fatigue, then what is the mechanism of the fatiguing? The authors have allowed that a chemically active environment can affect the fatigue properties of a solid material. Two possible contributors that may need to be considered are $(a)$ partial dissociations of the liquid to free radicals and chemical attack on portions of the solid, (b) partial dissociations to free radicals and penetration of the solid by hydrogen atoms.

The chemical inertness of a liquid does not guarantee an environment free of chemical activity once cavitation occurs. Intensely active molecular fragments of short life are likely produced momentarily and locally from toluene as well as from water molecules, by partial dissociations, either at the cavity collapse-points or along the solid surface by shock-wave impacts. ${ }^{7}$ These fragments include free atoms and free radicals such as $\mathrm{H} \cdot$, $\cdot \mathrm{OH}, \cdot \mathrm{OOH}, \cdot \mathrm{CH}_{3}, \cdot \mathrm{C}_{6} \mathrm{H}_{5}, \cdot \mathrm{C}_{6} \mathrm{H}_{5} \mathrm{CH}_{2}$, note that these are not ions. Free radicals are known to play vital roles in extremely fast chemical reactions such as flames and explosions, and are reported to cause adjacent stable substances to break down or become labile along with them. A stable metal surface (particularly of a good catalyst like nickel, iron, copper, or palladium) probably becomes so activated in the local presence of radicals from cavitation that its atoms participate in chemical reactions impossible elsewhere. Other reactions would concurrently restore the metal atoms, but not necessarily in the same exact place.

Also, there is a likelihood of penetration into the solid, by some of the free hydrogen atoms or by hydrogen molecules. Inter-

- Senior Mechanical Equipment Engineer. The Lummus Company, New York, N. Y. Mem. ASME.

7 "Cavitation Pitting by Instantaneous Chemical Action From Impacts," by Irving Taylor, ASME Paper No. 54-A-109. stitial hydrogen seems to make titanium alloys become brittle. This possibility of hydrogen penetration-through impacts and shock waves, partial dissociations, more impacts and shock waves-could well be an intermediate step between the beginning of cavitation and the finding of cold-work or deformation. The hydrogen inside the lattice, some of it still active chemically, could bring about "unbindings" or "loosening" of metal atoms one from another. Would not the x-ray patterns also be changed before any microscopic cracks could be observed?

Despite the weight of the authors' evidence there remains some uncertainty that the first deformations after exposure to cavitation are due to cavitation stresses alone-at least on the more resistant materials. As in the somewhat analogous phenomenon of fretting corrosion analyzed by $\mathrm{H}$. H. Uhlig, ${ }^{8}$ a combination of mechanical and chemical factors may comprise the mechanism of cavitation damage.

\section{Authors' Closure}

We wish to correct a possible misinterpretation which might arise from Mr. Taylor's opening remark that "The authors have very nearly proved that chemical actions play no part in the mechanism of cavitation pitting." We may reiterate our statement: "It is to be concluded that, in so far as the basic process of cavitation damage is concerned, chemical effects are not of primary significance. It must not be concluded that there are no chemical effects at all; in fact, it is known that a chemically active environment can affect the fatigue properties of a solid material."

The point under discussion is whether distilled water or liquid toluene are chemically active environments or not. Mr. Taylor proposes that these inert liquids become active through dissociation into free atoms or radicals. It is to be observed that the dissociation of water into $\mathrm{H}$ and $\mathrm{OH}$ requires an energy of 5.14 electron volts; to break a carbon-hydrogen bond in an organic molecule requires on the average about 4.3 electron volts, and to break a carbon-carbon bond requires on the average about 3.4 electron volts. Since 1 electron volt $=23.6$ kilocalories per mole, it follows that we are concerned with activation energies for the dissociation of water or toluene in the neighborhood of 80 to 100 kilocalories per mole. Now a shock wave in a liquid can only supply this energy by shock heating. It appears that the shocks of concern have pressure jumps of about 100,000 psi or less and a computation of the temperature rise for such shocks in water or toluene gives a temperature rise of less than $20 \mathrm{C}$. It follows that these shock waves cannot produce dissociation of the liquid. The possibility remains that higher temperatures may be encountered in the vapor of the cavitation bubbles when they are collapsed. Even if dissociation occurs at the point of collapse, the lifetime of the dissociation products is so small that it may be presumed that recombination would take place before they could diffuse through the liquid to the solid surface.

Our observations all point to the interpretation of cavitation damage as arising primarily from repeated application of high stresses of short duration which accompany vapor bubble collapse. Any attempt to explain the phenomenon by chemical dissociation in the liquid would seem to be based on unlikely speculations.

8 "Mechanism of Fretting Corrosion" by $\mathbf{H}, \mathbf{H}$. Uhlig, Journal of Applied Mechanics, Trans. ASME, vol. 76, 1954, pp. 401-407. 